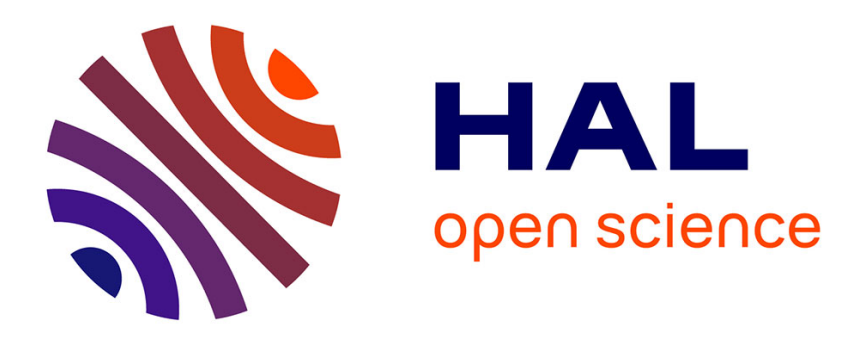

\title{
Three-Hybrid Screens: Inducible Third-Party Systems
}

Björn Sandrock, Franck Tirode, Jean-Marc Egly

\section{To cite this version:}

Björn Sandrock, Franck Tirode, Jean-Marc Egly. Three-Hybrid Screens: Inducible Third-Party Systems. Two-Hybrid Systems, 177, Humana Press, pp.271-289, 2001, 10.1385/1-59259-210-4:271. inserm-02438621

\section{HAL Id: inserm-02438621 https://www.hal.inserm.fr/inserm-02438621}

Submitted on 28 Jan 2020

HAL is a multi-disciplinary open access archive for the deposit and dissemination of scientific research documents, whether they are published or not. The documents may come from teaching and research institutions in France or abroad, or from public or private research centers.
L'archive ouverte pluridisciplinaire HAL, est destinée au dépôt et à la diffusion de documents scientifiques de niveau recherche, publiés ou non, émanant des établissements d'enseignement et de recherche français ou étrangers, des laboratoires publics ou privés. 
Methods in molecular biology: Two Hybrid System, Methods and protocols

\section{5 \\ Three-hybrid screens: inducible third-party systems}

Björn Sandrock, Franck Tirode, and Jean-Marc Egly

Institut de Génétique et de Biologie Moléculaire et Cellulaire, CNRS / INSERM/ULP; B.P.163, 67404 Illkirch Cedex; C.U. de Strasbourg, France Tel.: 003338865 3447; Fax: 003338865 3201; e-mail: egly@igbmc.u-strasbg.fr 


\section{5 - Three-hybrid screens: inducible third-party systems}

\section{INTRODUCTION}

Recent studies have brought up the existence of several molecular complexes either stable, like the RNA polymerase II holoenzyme, transcription factor TFIID and mediators, or transient as could be observed in the various steps of the transcription process e.g. initiation, elongation and termination. These observations point out the fact that regulation of different cellular mechanisms is orchestrated by interactions between molecular species either to modify proteins or to position one of them within a complex that then will be functional. Several techniques such as affinity precipitation, glycerol gradient sedimentation and the yeast two-hybrid system are currently used to study protein-protein interactions (1). These various methods, usually investigating the connection between two partners, keep in account only the strong (and stable) interactions and neglect the weaker ones. Considering the complexes studied so far, it is suspected and sometimes shown that interactions often occur between more than two proteins, e.g. to stabilize the complex. In an effort to understand the various biological mechanisms -and in our case gene expression regulation-, we were interested in developing the yeast three-(or tri-)hybrid system.

The three-hybrid system, as illustrated in figure 1 , is based on the reconstitution of a transcriptional activator complex either to search for or to study a protein that interacts with two others and to acquire information about ternary complex assembly (2). This technique detects direct or mediated interactions between two fusion proteins that contain either a DNA binding domain (DBD; the DBD-X protein) or an activation domain (AD; the $\mathrm{AD}-\mathrm{Y}$ protein). In some cases, when these two hybrid proteins interact weakly or not at all, a third partner (the protein $\mathrm{Z}$ ) is necessary to promote (to induce) the formation of the transcriptional activator allowing the transcription of the reporter genes. Thus, specific and stable protein-protein interactions between $X, Y$ and $Z$ lead to the activation of the reporter genes that are integrated in the yeast genome. The HIS3 reporter gene contains a specific DNA sequence which can be recognized by the DBD of the transcriptional activator. Activation of the HIS3 gene permits the endogenous synthesis of histidine allowing the yeast to grow on histidine-lacking media. Activation of the Lac Z gene, another reporter gene containing the same DNA binding element, will lead to the synthesis of the $\beta$-galactosidase $(\beta$-Gal) that catalyses the transformation of either X-Gal (5-bromo4-chloro-3-indolyl $\beta$-D-galactopyranoside) or ONPG (o-nitrophenyl- $\beta$-Dgalactopyranoside) into a detectable blue or yellow product, respectively.

There are several options to reconstitute the transcriptional activator: (i) the third partner $Z$ can act as a bridging factor (Fig.1A) by interacting with both the DBD-X and $A D-Y$, thus allowing the DNA-binding protein $X$ to target the basal transcription machinery; (ii) In case of weak interactions, $Z$ may function as a stabilising factor (Fig.1B) that strengthens the interaction between $X$ and $Y$; (iii) In some other cases, reconstitution of the transcriptional activator requires some post-transcriptional modifications of one of the two partners, in order to allow interaction between $X$ and $\mathrm{Y}$. The third partner $\mathrm{Z}$ will then be a regulating factor (Fig.1C), an enzyme that will not necessarily be part of the reconstituted transcriptional activator.

When DBD-X and AD-Y are sufficient to reconstitute a stable transcriptional activator, the three-hybrid system can also be used for the search of inhibitors. In this case, the $\mathrm{Z}$ partner can act as an inhibitor (Fig.1D) by interacting with, or enzymatically modifying, one of the two main partners, thus preventing their interactions. This will result in the inhibition of the expression of the reporter genes followed by growth restriction on histidine-lacking media as well as repression of the $\beta$-Gal activity. 
In order to control the specificity of the ternary complex formation that depends on the expression of one of its components, we have set up an inducible three-hybrid system, in which the expression of the third partner Z can be easily switched "on" or "off". Therefore we have used the already characterized yeast Met25 promoter (3). Excess of methionine in the culture medium leads to the transcriptional repression of a cDNA cloned downstream of this promoter. Thus, we have designed the two plasmids, pBridge and pLexA9-3H (Fig.2, left panel), containing first the DNA of either GAL4 or second LexA DBD, which can be fused to the cDNA of the X protein, and second the methionine regulated expression cassette, containing the Met25 promoter, which can be fused to the cDNA of the third partner Z.
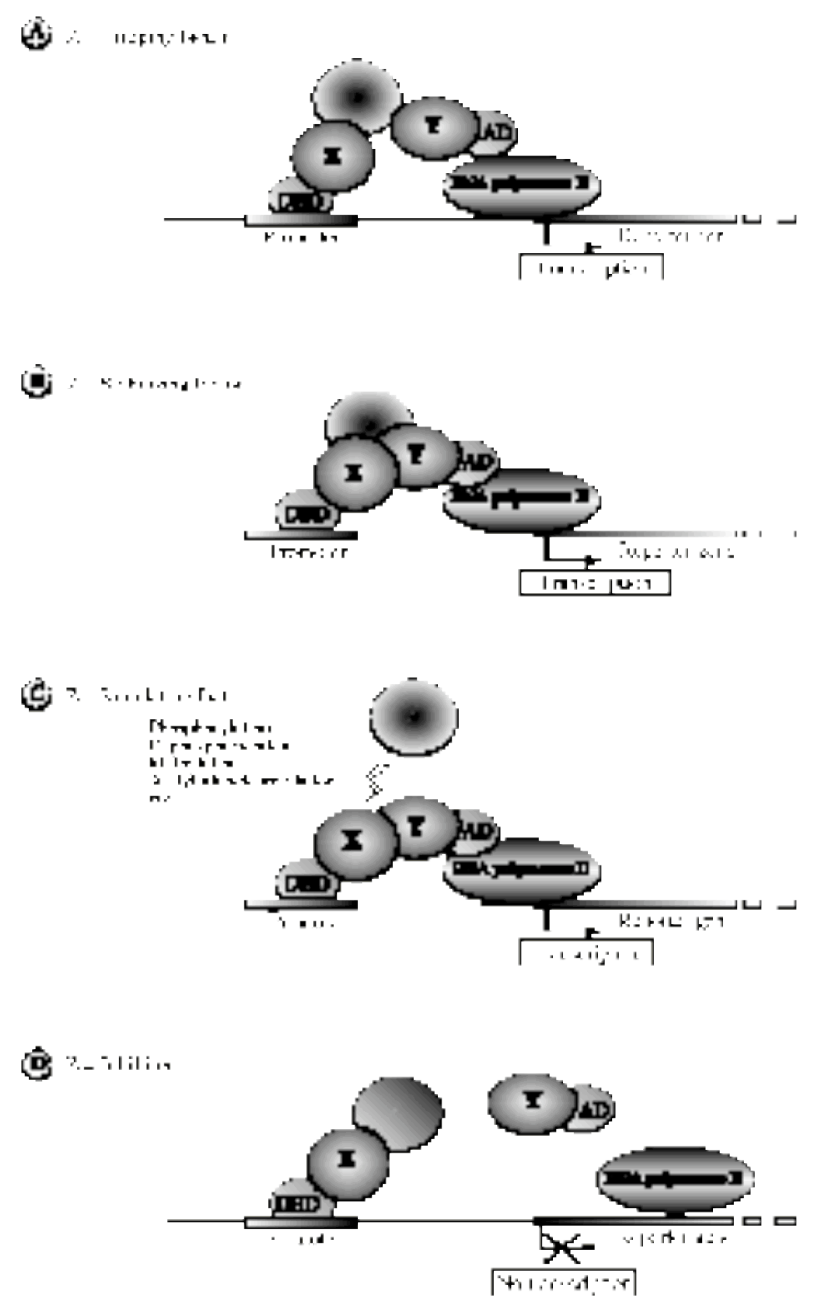

Figure 1: The three-hybrid system

The three-hybrid system can be used to characterise or detect new factors such as (A) a bridging factor $Z$, which interacts with both proteins, $X$ and $Y$, that do not interact each other, (B) a stabilising factor $Z$ that strengthens a weak interaction between the two proteins $X$ and $Y,(C)$ a regulating factor $Z$ that stimulates the interaction between the two fused proteins $X$ and $Y$ by modifying one of them, (D) an inhibitor $Z$ that prevents the interaction between two interacting proteins $X$ and $Y$. In the three first cases, upon expression of the third partner $(Z)$ the transcriptional activator formed stimulates the transcription of the reporter genes whereas in the last case, the third polypeptide inhibits the transcriptional activator formation thus preventing the transcription of the reporter genes.

\subsection{The inducible third partner $\mathrm{Z}$ as Activator}

In order to reconstitute the transcriptional activator, the third partner $Z$ (as shown in Figure.1: $A, B, C)$ can be overexpressed in the absence of methionine. We have illustrated this feature with the formation of the cdk-activating kinase (CAK) that 
contains three subunits: a cyclin dependent-kinase, cdk7, the cyclin H and MAT1, a stimulatory factor (4). Although the role of CAK, a subcomplex of the multiprotein complex TFIIH, is not well known in the various events that regulate the cell cycle cascade, it seems to play a role in protein coding gene transcription through the phosphorylation of the carboxy-terminal domain (CTD) of RNA polymerase II (5). It has been shown that cdk7 and cyclin $\mathrm{H}$ interact with each other but the role of MAT1 in the assembly of CAK was still unknown $(6,7)$. Using the three-hybrid system, we could demonstrate that the weak interaction between the two fused proteins DBDcdk7 (X) and AD-MAT1 (Y) was stabilized upon expression of the third partner, cyclin $\mathrm{H}(\mathrm{Z})$, cloned in the Met25 expression cassette (8). This assembly does not occur in the presence of methionine that prevents the expression of cyclin $\mathrm{H}$. This assay shows, that MAT1 contacts cdk7 or integrates the CAK complex in the presence of cyclin $\mathrm{H}$.

The inducible three-hybrid system could be used to screen a cDNA library in order to search for some activating partners. Therefore two different screenings are possible: 1.) To identify proteins ( $Y$ ) that may target an already formed binary complex (X-Z; see Fig.1A), the screening is made with a cDNA library inserted downstream of the activation domain (AD) sequence like most of the commercially available cDNA libraries. In this case, in order to isolate positive clones, yeast growth will be performed on a medium lacking methionine; the colonies will then be replicaplated on a medium containing both methionine and X-Gal on which they will no longer grow or stay white. 2.) To identify proteins $(Z)$ that stabilize or regulate a weak interaction $(X-Y$; see Fig.1B,C), the cDNA-library must be cloned downstream of the Met25 promoter. The screening is then made on a histidine-lacking medium in the absence of methionine. Positive clones will be identified through a replica-plating on methionine-containing medium as mentioned above.

\subsection{The inducible partner $Z$ as Inhibitor}

As an example to investigate $\mathrm{Z}$ components that target either $\mathrm{X}$ or $\mathrm{Y}$ proteins and consequently prevent the reconstitution of the transcriptional activator, we studied two oncogenic proteins, Raf and Ras (9), involved in signal transduction. The fused DBD-Ras $(X)$ and AD-Raf $(Y)$ proteins specifically interact each other in a two-hybrid system (9). An inhibition of the transcription of the reporter gene can be observed (8) in the absence of interaction between DBD-Ras (X) and AD-Raf (Y). This may occur when the cDNA of a nonfused cRaf is cloned downstream of the Met25 promoter and further expressed as the third partner $(Z)$ in the absence of methionine. In this case, cRaf $(Z)$ competes with AD-Raf $(Y)$ for targetting DBD-Ras $(X)$. Because the Met25 promoter is stronger than the hybrid gene promoter (3), its activation (in absence of methionine) leads to an excess of cRaf titrating out the DBD-Ras. Thus the transcriptional activator will not be reconstituted resulting in the repression of the reporter genes.

\section{MATERIALS}

\subsection{Growth and maintenance of yeast}

1. YPD Medium: $20 \mathrm{~g} / 1$ Bacto $^{\mathrm{TM}}$ Peptone (Difco); $10 \mathrm{~g} / 1$ yeast extract (Difco); $20 \mathrm{~g} / 1$ $\mathrm{D}(+)$-Glucose (Riedel-deHaën, Germany); water to $1 \mathrm{l}$; autoclave at $121^{\circ} \mathrm{C}$ for $15 \mathrm{~min}$ (or add water to $950 \mathrm{ml}$; autoclave for $30 \mathrm{~min}$, then add $50 \mathrm{ml}$ sterile filtrated $40 \%$ D(+)-Glucose). For culture plates add $20 \mathrm{~g} / 1$ Agar (Difco).

2. Yeast-Minimal Medium (MM): $6.7 \mathrm{~g} / 1$ yeast nitrogen base without amino acids (Difco); $20 \mathrm{~g} / 1 \mathrm{D}(+)$-Glucose; water to 11 ; autoclave at $121^{\circ} \mathrm{C}$ for $15 \mathrm{~min}$ (or add water to $950 \mathrm{ml}$; autoclave for $30 \mathrm{~min}$, then add $50 \mathrm{ml} \mathrm{40 \%} \mathrm{D(+)-Glucose).} \mathrm{For} \mathrm{culture} \mathrm{plates}$ add $20 \mathrm{~g} / 1$ Agar. Depending on the different strains the following amounts of specific 
nutrients should be added (either as a tenfold stock for small volumes or directly as powder for higher volumes) except the one(s) for which the medium should select: $0.2 \mathrm{~g} / 1$ L-Tryptophane; $0.2 \mathrm{~g} / 1$ L-Histidine; $0.2 \mathrm{~g} / 1$ L-Adenine; $1.0 \mathrm{~g} / 1$ L-Leucine 0.3 $\mathrm{g} / 1$ L-Lysine; $0.2 \mathrm{~g} / 1$ Uracile (Sigma).

3. $90 \mathrm{~mm}$ (Greiner) and $245^{\star} 245 \mathrm{~mm}$ (PolyLabo) culture plates.

\subsection{Transformation}

1. Stock solutions: 50\% PolyEthylenGlycol 4000 (MERCK; sterile filtrated); $100 \%$ Dimethyl sulfoxyde (DMSO; MERCK); 10x LiAc: 1 M Lithium acetate (Sigma), pH 7.5 (autoclave); 10x TE buffer: $0.1 \mathrm{M}$ Tris- $\mathrm{HCl}, 10 \mathrm{mM}$ EDTA, pH 7.5 (autoclave); $10 \mathrm{mg} / \mathrm{ml} \mathrm{Herring} \mathrm{testis} \mathrm{carrier} \mathrm{DNA} \mathrm{(Sigma;} \mathrm{boil} \mathrm{just} \mathrm{prior} \mathrm{use} \mathrm{for} 5 \mathrm{~min}$, then cool on ice).

2. TE/LiAc: $1 x$ TE, $1 x$ LiAc.

3. PEG/LiAc: $40 \%$ PEG, 1x TE, 1x LiAc.

4. Appropriate minimal medium containing plate.

\subsection{Methionine selection}

1. Yeast minimal medium as described in subheading 2.1.

2. Methionine stock: We prepare a $0.2 \mu \mathrm{m}$ filtered $1 \mathrm{M}$ L-methionine (Sigma) in deionized $\mathrm{H}_{2} \mathrm{O}$. This solution can be frozen to $-20^{\circ} \mathrm{C}$ and kept for years.

Minimal medium is supplemented with $1 \mathrm{mM}$ L-methionine.

3. 3-Amino-1,2,4-triazole (3AT; Sigma).

\subsubsection{Protein extraction}

\subsection{Protein extraction and immunopurification}

1. Extraction buffer: $50 \mathrm{mM}$ Tris- $\mathrm{HCl} \mathrm{pH} 7.8,10 \%$ Glycerol, $0.1 \mathrm{mM}$ EDTA, 100$300 \mathrm{mM} \mathrm{KCl}, 1 \mathrm{mM}$ PhenylMethylSulfonylFluoride (PMSF; Sigma) and 1x protease inhibitor cocktail (Roche Diagnostics; contains Leupeptine, Pepstatin, Aproptinin, Antipain and Chimostatin).

2. Acid treated glass beads (Sigma).

3. A $0.45 \mu \mathrm{m}$ microspin-column (Ultrafree-MC; Millipore) is used to remove the biggest particles.

\subsubsection{Immunopurification}

1. Antibodies are crosslinked to protein A-Sepharose CL-4B (AP Biotech).

2. Stock solutions: $5 \mathrm{M} \mathrm{NaCl} ; 1 \mathrm{M}$ Sodium Borate $\mathrm{pH}$ 9; $0.2 \mathrm{M}$ Ethanolamine $\mathrm{pH}$ 8; $10 \mathrm{mg} / \mathrm{ml}$ BSA.

3. Sodium Azide (Sigma), Dimethyl Pimelidate (DMP; ICN Pharmaceuticals).

4. Buffers: $\mathrm{TG}_{10} \mathrm{EK}_{\mathrm{X}}$ : $20 \mathrm{mM}$ Tris- $\mathrm{HCl} \mathrm{pH} 7.8,10 \%$ Glycerol, $0.1 \mathrm{mM}$ EDTA, $\mathrm{X} \mathrm{mM} \mathrm{KCl}$.

Crosslink wash buffer: $3 \mathrm{M} \mathrm{NaCl}, 50 \mathrm{mM}$ Na Borate $\mathrm{pH} 9$.

Crosslinking buffer: $3 \mathrm{M} \mathrm{NaCl}, 200 \mathrm{mM}$ Na Borate pH 9, $20 \mathrm{mM}$ DMP.

Elution buffer: $\mathrm{TG}_{10} \mathrm{EK}_{50} ; 0.01 \% \mathrm{NP} 40 ; 0.2 \mathrm{mg} / \mathrm{ml}$ insuline; $2 \mathrm{mg} / \mathrm{ml}$ peptide corresponding to the epitope.

\section{5. $\beta$-Gal assays}

Stock solution: Z-buffer: $21.5 \mathrm{~g} / 1 \mathrm{Na}_{2} \mathrm{HPO}_{4} \cdot 12 \mathrm{H}_{2} \mathrm{O} ; 5.5 \mathrm{~g} / 1 \mathrm{NaH}_{2} \mathrm{PO}_{4} \cdot \mathrm{H}_{2} \mathrm{O} ; 0.75 \mathrm{~g} / 1$ $\mathrm{KCl} ; 0.246 \mathrm{~g} / 1 \mathrm{MgSO}_{4} \cdot 7 \mathrm{H}_{2} \mathrm{O}$; adjust to $\mathrm{pH} 7.0$ and autoclave.

\subsubsection{Colony lift filter assays}

For LexA-transformants, use plates which contain MM with 2\% D(+)-Galactose and $1 \%$ Raffinose instead of $\mathrm{D}(+)$-Glucose.

1. Hybond ${ }^{\mathrm{TM}}$ Nylon membranes (Amersham); 3MM Whatman paper; liquid Nitrogen. 
2. X-Gal (5-Bromo-4-chloro-3-indolyl- $\beta$-D-galactopyranoside; Merck) solution: $20 \mathrm{mg}$ $\mathrm{X}-\mathrm{Gal} / \mathrm{ml}$ of N,N-Dimethylformamide (DMF; Sigma); store in the dark at $-20^{\circ} \mathrm{C}$.

3. Z-M-X-buffer: $100 \mathrm{ml} \mathrm{Z-Buffer;} 0.27 \mathrm{ml} \beta$-Mercaptoethanol; $1.67 \mathrm{ml} \mathrm{X-Gal} \mathrm{solution.}$

\subsubsection{Liquid culture assay}

1. Z-M-buffer: $100 \mathrm{ml} Z$-buffer; $0.27 \mathrm{ml} \beta$-Mercaptoethanol.

2. Z-O solution: dissolve $4 \mathrm{mg}$ ONPG (o-nitrophenyl- $\beta$-D-galactopyranoside; Sigma)/ $\mathrm{ml}$ Z-buffer (prepare ca. 1 hour before each use).

3. $1 \mathrm{M} \mathrm{Na}_{2} \mathrm{CO}_{3}$

\subsubsection{On-plate assay}

1. 10x S-buffer (for $500 \mathrm{ml}$ ): $68 \mathrm{~g} \mathrm{KH}_{2} \mathrm{PO}_{4}, 9.9 \mathrm{~g}\left(\mathrm{NH}_{4}\right)_{2} \mathrm{SO}_{4}, 21 \mathrm{~g} \mathrm{KOH}$; $\mathrm{pH} \approx 8.0$.

$\mathrm{X}-\mathrm{Gal}$ : as described under subheading 2.5.1.

2. Minimal medium as described under subheading 2.1.

\section{METHODS}

\subsection{Growth and maintenance of yeast}

Working with yeast should be done under sterile conditions, because the different culture media do not contain antibiotics. Thus, contaminations should be avoided using sterile glass and plastic ware. It is recommanded to work at a cleanbench or beside a burning flame.

\subsubsection{Yeast strains}

The strains used in the three-hybrid system are the same that the ones used for the two-hybrid. There are different yeast strains either more or less sensitive for the detection of protein-protein interactions, depending on the vectors, the transcriptional activator (Gal4 or LexA-VP16) and the protein used as the bait (see note 4.1.). The most common yeast strains are the L40 strain (MATa, trp1, his3, leu2, ade2, LYS2::(LexAop) ${ }_{4}$-HIS3, URA3::(LexAop) $)_{8}$-LacZ) for the LexA-VP16 system and the HF7c strain (ura3, his3, lys2, ade2, trp1, leu2, LYS2::Gal1 ${ }_{\mathrm{UAS}}-\mathrm{Gal1}_{\mathrm{TATA}}$-HIS3, URA3::GAL4 ${ }_{17 \text { mersx3, }}$ CyC1 ${ }_{\text {TATA }}$-lacZ) or the Y190 (ura3, his3, lys2, ade2, trp1, leu2, cyhr2, LYS2::Gal1 ${ }_{\text {UAS }}$-HIS3 ${ }_{\text {TATA }}$-HIS3, URA3::GAL1 ${ }_{U A S}-G A L 1_{\text {TATA }}$-lacZ) when using the GAL4 system. These strains are commercially available.

\subsubsection{Yeast amplification}

Freshly streaked yeast grow at $28^{\circ} \mathrm{C}$ for $4-5$ days until colonies are $1-2 \mathrm{~mm}$ in diameter. One such colony can then be used for amplification in liquid culture. For the maintenance of yeast strains, a colony resuspended in $0.5 \mathrm{ml}$ of sterile water should be restreaked every 6-8 weeks. For long-time storage yeast strains can be stored in the appropriate medium containing $15 \%$ glycerol at $-70^{\circ} \mathrm{C}$.

\subsection{Plasmid constructs}

For the activation experiments we used the LexA-VP16 system. Thus, the bait (cdk7) is linked to the DBD of LexA in pLex9-3H (Fig.2; left panel) carrying the TRP1 selection gene that allows growth on tryptophane lacking MM. The second partner (MAT1), which has no significant interaction properties with the bait, is fused to the AD of VP16 in pVP16 (Fig.2; right panel), containing the LEU2 selection gene that allows growth on leucine lacking MM. In addition, the cDNA of the third partner (cyclin $\mathrm{H}$ ) is cloned in the Met25 expression cassette (see note 4.2.), which is on the same plasmid as the bait (pLex9-3H).

For the inhibition experiments we used the GAL4 system, in which the bait $(\mathrm{H}-$ Ras(V12)) is fused to the DBD of GAL4 in pBridge and the interacting partner (cRaf1) 
is added behind the AD of GAL4 in pGAD-GH. The cDNA of the third partner (cRAF1) is cloned into the Met25 expression cassette, which is on the same plasmid as the bait (pBridge).
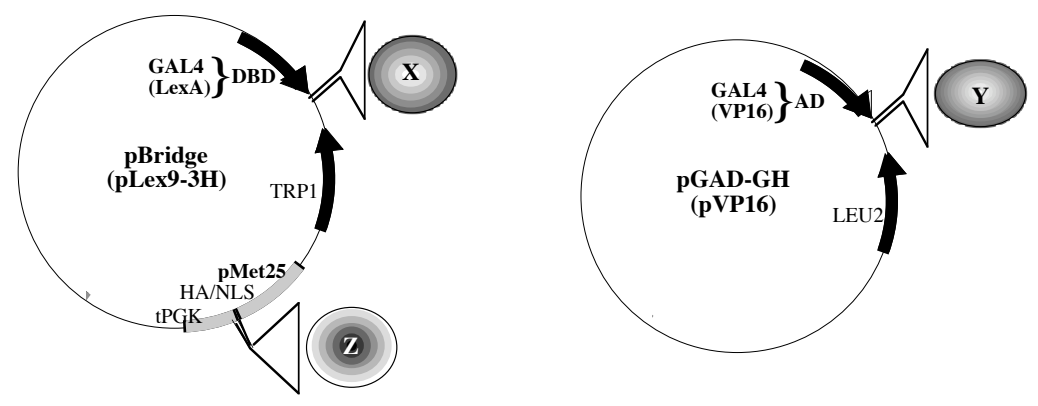

Figure 2: The three-hybrid vectors:

Left panel: pBridge, derived from the pGBT9 vector, contains the TRP1 selective gene, the DNAbinding domain of GAL4 and the Met25 expression cassette (see note 4.2.) with the NotI and BgIII cloning sites. pLex9-3H, derived from the pBTM116 vector, contains the TRP1 selective gene, the DNA-binding domain of LexA and the Met25 expression cassette with the NotI and SrfI cloning sites. The Met25 cassette contains a hemagglutinine (HA) tag sequence, a nuclear localisation signal (NLS) sequence and the terminator of the phosphoglycerate kinase (tPGK). Right panel: The plasmids pGAD$\mathrm{GH}$ and pVP16 contain the LEU2 selective gene and the activation domain of GAL4 and VP16, respectively.

\subsection{Transformation}

To introduce plasmid DNA into yeast, the LiAc-mediated transformation is very easy, fast and reproducible. The method described here allows single transformation or simultanous cotransformation of two different plasmids carrying different selection genes. Our protocol can be used for up to 10 parallel transformations but can easily be scaled-up. Furthermore, with this method a cDNA library transformation can be performed; the culture or buffer volumes are indicated in brackets. It is important to mention that a positive and a negative control should be incorporated to demonstrate the efficiency of the transformation. This efficiency should be around $10^{5}$ colonies / $\mu$ g plasmid for a single transformation.

1. Inoculate $10 \mathrm{ml}$ of YPD or the appropriate MM with a single colony of about $2 \mathrm{~mm}$ in diameter and incubate overnight at $28^{\circ} \mathrm{C}$. (For the library screening, further inoculate $150 \mathrm{ml}$ of the same medium with the $10 \mathrm{ml}$ of the preculture and let grow overnight.) Dilute the suspension to an $\mathrm{OD}_{600}$ of 0.2 to 0.3 and incubate the culture for approximately 3 hours to get an $\mathrm{OD}_{600}$ around $0.5 \pm 0.1$ (the log phase).

2. Centrifuge $50 \mathrm{ml}(1000 \mathrm{ml})$ of the culture for $5 \mathrm{~min}$ at $1000 \mathrm{~g}$. Discard the supernatant and wash the cells in $30 \mathrm{ml}(500 \mathrm{ml})$ of sterile water. After a second centrifugation step, resuspend the cells in $1 \mathrm{ml}(8 \mathrm{ml})$ sterile TE/ LiAC.

3. Mix $0.1 \mathrm{mg}(20 \mathrm{mg})$ herring sperm DNA with $0.1 \mu \mathrm{g}$ of each plasmid -for simultaneous cotransformation use $0.2 \mu \mathrm{g}$ of each different plasmid- $(0,5 \mathrm{mg}$ cDNA library) in a sterile $1.5 \mathrm{ml}(500 \mathrm{ml})$ tube and add $100 \mu \mathrm{l}(8 \mathrm{ml})$ of the yeast solution. Mix vigorously and add $600 \mu \mathrm{l}(60 \mathrm{ml})$ PEG/LiAc. Vortex and incubate for $30 \mathrm{~min}$ at $30^{\circ} \mathrm{C}$ with shaking (200 rpm).

4. Add $70 \mu \mathrm{l}(7 \mathrm{ml})$ DMSO, mix carefully by inverting the tubes and incubate for $15 \mathrm{~min}$ at $42^{\circ} \mathrm{C}$. Centrifuge for $20 \mathrm{sec}(5 \mathrm{~min})$ at $13000 \mathrm{rpm}$ and remove the supernatant. Dissolve the yeast-pellet in $500 \mu \mathrm{l}(10 \mathrm{ml}) \mathrm{TE}$ and plate $100 \mu \mathrm{l}(200 \mu \mathrm{l})$ of this suspension on a $90 \mathrm{~mm}\left(245^{\star} 245 \mathrm{~mm}\right)$ plate which allows selection for the desired transformant(s).

5. Incubate the plate(s) at $30^{\circ} \mathrm{C}$ until the colonies are 1-2 $\mathrm{mm}$ in diameter (4-5 days). 


\subsection{Methionine selection}

The advantage of the three-hybrid system using the Met25 inducible promoter resides in the "on" or "off" switch for the expression of the third protein (see note 4.3.). A simple replica-plating experiment allows to quickly check the interaction specificity between the various partners:

1. Select at least three different clones from the leucine and tryptophane lacking plates selective for both plasmids. Scrape the whole colony and resuspend in $100 \mu \mathrm{l}$ of sterile $\mathrm{H}_{2} \mathrm{O}$.

2. Make one to ten dilutions in sterile $\mathrm{H}_{2} \mathrm{O}$ up to $10^{-4}$.

3. Drop $10 \mu \mathrm{l}$ of each dilutions either on selective MM plates containing or lacking $1 \mathrm{~m} M$ methionine.

4. Let the yeast grow 4 days at $28^{\circ} \mathrm{C}$. The duration of the growth may be dependent on the proteins expressed and can take up to 10 days.
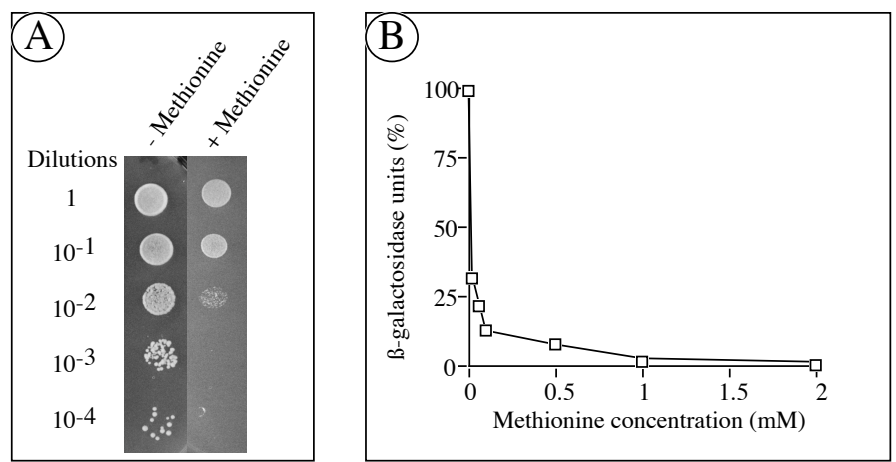

Figure 3: A. L40 yeast cells cotransformed with pLex9-3H, containing LexA-cdk7 and cyclin H under the dependence of the Met25 promoter, and with MAT1pVP16 were spotted at various dilutions, as indicated at the left of the figure, on a selective minimal medium lacking histidine. Yeast growth was performed during 4 days at $30^{\circ} \mathrm{C}$, in absence (-) or presence $(+)$ of $1 \mathrm{mM}$ methionine, controlling the expression of the third partner, cyclin H. In presence of the third partner we can observe a yeast growth for the highest dilutions whereas in presence of methionine, and so in absence of the cyclin $\mathrm{H}$, we can observe yeast growth only for the first dilutions. B. $\beta$-Galactosidase assay from liquid culture of pLex9-3H/cdk7/Met-cyclinH-pVP16/MAT1 cotransformed yeast was done as described in subheading 3.6.2. The $\beta$-Gal activity was measured as a function of the methionine concentration and so as a function of the presence of the third partner. The interaction, reflected by the $\beta$-Gal activity, is no more detectable in presence of $1 \mathrm{mM}$ methionine. $100 \%$ corresponds to the $\beta$-Gal activity of the yeast grown on a methionine lacking medium and $0 \%$ to the activity of yeast grown on a $10 \mathrm{mM}$ methionine containing medium.

An example of the methionine dependent reconstitution of the transcriptional activator is shown in figure 3A. The three proteins of the TFIIH CAK complex (constructions described in subheading 3.2.) were expressed in yeast. Cyclin $\mathrm{H}$ is conditionally expressed from the Met25 promoter. The complex is then formed only if the three proteins are present. Thus, the yeast are able to grow in the absence of methionine because the cyclin $\mathrm{H}$ is expressed and the ternary complex is reconstituted leading to the transcriptional activation of the reporter genes. The colonies that are plated on selective MM lacking $1 \mathrm{mM}$ methionine grow faster than colonies plated on MM containing methionine. Thus, the methionine repression is observed for the $10^{-2}$ to $10^{-4}$ dilutions. Because of a weak interaction between DBDcdk7 and AD-MAT1, a background growth can be observed for the lower dilutions. Furthermore, non-specific interactions can take place between one of the hybrid proteins and the fused DBD directly. In order to remove these background, 3-Amino1,2,4-triazole (3AT; between 5 and $50 \mathrm{mM}$ ) can therefore be added to the medium. Moreover, the Met25 promoter is known to be leaky, meaning that the expression of 
the third partner, cyclin $\mathrm{H}$, is not completely repressed, resulting in some detection of yeast growth on a methionine containing medium.

As shown above, the Met25 promoter is down regulated upon addition of methionine. To determine the optimum conditions of the methionine repression, several concentrations have been tested out using the liquid $\beta$-galactosidase assay (see subheading 3.6.2) with the system containing the three proteins of the CAK complex, as described above. Thus, the resulting $\beta$-Gal activity, corresponding to the concentration of the third partner, was measured as a function of the methionine concentration. As shown in figure 3B, the $\beta$-Gal activity, reflecting the cyclin $\mathrm{H}$ expression, is about $30 \%$ of the activity without methionine for $0.01 \mathrm{mM}$ methionine, $10 \%$ for a concentration of $0.5 \mathrm{mM}$ and completely repressed for $1 \mathrm{mM}$. Actually, this system can also be useful for the control of the expression of toxic proteins, in order to decrease the amount of these proteins in the cell.

\subsubsection{Protein extraction}

\subsection{Protein extraction and immunopurification}

To investigate whether or not the hybrid-proteins are well expressed, it is necessary to prepare yeast protein extracts and to perform western-blotting assays.

1. Inoculate $50 \mathrm{ml}$ of selective medium for the plasmids (described in subheading 2.1.) to $\mathrm{OD}_{600}$ of 0.05 . Grow at $28^{\circ} \mathrm{C}$ with shaking until an $\mathrm{OD}_{600}$ between 0.8 and 1 . Depending on the protein that is expressed, the growth can take between over-night and 3 days.

2. Transfer the culture in a $50 \mathrm{ml}$ tube and cool the cells by placing the tube on ice for few minutes. Centrifuge $5 \mathrm{~min}$ at $3000 \mathrm{rpm}, 4^{\circ} \mathrm{C}$.

3. Resuspend the cell pellet in $1 \mathrm{ml}$ cold $\mathrm{H}_{2} \mathrm{O}$, transfer to a microfuge tube, centrifuge $30 \mathrm{sec}$. at maximum speed, remove the supernatant and add $300 \mu \mathrm{l}$ of extraction buffer. Different buffers can be used for the extraction but usually a high salt buffer $(300 \mathrm{mM} \mathrm{KCl})$ is recommended for a higher recovery. To analyse the in vitrointeraction between the hybrid proteins using immunoprecipitation or immunopurification assays, the cell pellet should be resuspended at this stage in a low salt extraction buffer $(100 \mathrm{mM} \mathrm{KCl})$, in order to retain potential weak interactions.

4. Add glass beads to 1-2 mm below the surface and keep on ice for 10 minutes.

5 . Vortex vigorously in cold room 3 times 1 minute with intervals of 1 minute on ice.

6. Centrifuge at maximum speed $(13000 \mathrm{rpm})$ for 15 minutes at $4^{\circ} \mathrm{C}$.

7. Transfer the supernatant to a microspin-column (Ultrafree-MC; Millipore) in order to filter residual big particles (see note 4.4.). Centrifuge $30 \mathrm{sec}$ at maximum speed.

8. Samples can be frozen at $-80^{\circ} \mathrm{C}$ and kept for several months.

9. Estimate the total protein concentration by performing a Bradford assay.

10. Run 10 to $100 \mu \mathrm{g}$ of protein on a SDS-PAGE (8 to 15\%) and perform a western blot.

\subsubsection{Immunoprecipitation of $\mathrm{HA}$ tagged protein from yeast}

The purification of a new protein, identified as an interacting partner during a cDNA library screening, is important for further analysis. It is therefore useful that the proteins expressed by the vectors containing the cDNA library are tagged.

We have introduced the hemagglutinine sequence corresponding to the HA-tag (SYPYDVPDYASLGGPSS, one amino acid code), upstream of the cloning site (Fig.2) in the methionine regulated expression cassette. Thus, the expressed protein can be immunoprecipitated or immunopurified directly from a yeast crude extract with a HA-tag specific antibody (commercially available). Instead of the HA-antibody, a specific antibody can as well be used in the following protocol. 
1. Antibody crosslink to protein A-Sepharose via DMP

a. Wash the protein A-Sepharose 3 times with 10 volumes of crosslink wash buffer.

b. Add 0.7 volume of purified anti-HA monoclonal antibody with 4.3 volumes of crosslink wash buffer. Incubate at RT $1 \mathrm{~h}$ under gentle shaking.

c. Wash 2 times with 10 volumes of crosslink wash buffer

d. Add 10 volumes of crosslinking buffer. DMP should be added immediately before use. Incubate $30 \mathrm{~min}$ at RT under gentle shaking.

e. Wash once with 10 volumes of Ethanolamine $0.2 \mathrm{M}$ and incubate with 10 volumes of Ethanolamine $0.2 \mathrm{M}$ at RT for $2 \mathrm{~h} 30$ or at $4^{\circ} \mathrm{C}$ over night.

f. Wash 2 times with 10 volumes of $\mathrm{TG}_{10} \mathrm{EK}_{300} / 0.05 \%$ NP40. The beads are then ready to use. If you want to keep the antibody crosslinked to protein A-Sepharose for several weeks, add $1 \mathrm{mg} / \mathrm{ml}$ BSA and $0.2 \%$ Na azide. Before use, wash then 3 times with 10 volumes of $\mathrm{TG}_{10} \mathrm{EK}_{300} / 0.05 \%$ NP40.

2. Immunoprecipitation of the HA tagged protein.

For a pull down assay, very little yeast extract is needed. Remember that if the strength of the interaction is not known, it is recommended to make the yeast extract at low salt concentration or to dialyse the extract against a low salt buffer.

a. Incubate $300 \mu \mathrm{l}$ of the yeast extract with $50 \mu \mathrm{l}$ of the antibody sample crosslinked to the protein A-Sepharose for at least 4 hours at $4^{\circ} \mathrm{C}$ under gentle shaking.

b. Wash the beads 3 times with $1 \mathrm{ml}$ of $\mathrm{TG}_{10} \mathrm{EK}_{100-500}$ (usually $300 \mathrm{mM} \mathrm{KCl}$ is preferred, once more depending on the strength of the interaction).

c. Add $50 \mu \mathrm{l}$ of Laemmli sample buffer to the beads removed of the supernatant and load (5-20 $\mu \mathrm{l})$ on a SDS-polyacrylamide gel.

\subsubsection{Immunopurification of the $\mathrm{HA}$ tagged protein.}

Using the three-hybrid system, it is possible to directly purify the protein under the control of the Met25 promoter as well as the tripartite complex. The immunoprecipitation procedure can be scaled up to 2 liters of yeast culture or even more, if necessary. We describe the method for a $20 \mathrm{ml}$ culture:

1. Proceed as in subheading 3.5.2. until step 2.b. After the $\mathrm{TG}_{10} \mathrm{EK}_{100-500}$ washings, wash 2 times more with $1 \mathrm{ml}$ of $\mathrm{TG}_{10} \mathrm{EK}_{50}$.

2. Remove the supernatant and add $50 \mu \mathrm{l}$ of elution buffer which contains the oligopeptide corresponding to the $\mathrm{HA}_{\llcorner}$or the specific antibody epitope. Incubate at $4^{\circ} \mathrm{C}$ over-night with gentle shaking.

3. Centrifuge at low speed (2000 rpm) for few seconds and transfer the supernatant to a microfuge tube. Centrifuge and transfer once more to discard all the remaining beads. Most of the time the oligopeptide does not interfere with the activity of the purified protein; if necessary, dialyse against $\mathrm{TG}_{10} \mathrm{EK}_{50}$ for 4 hours at $4^{\circ} \mathrm{C}$.

4 . Verify by western blot the presence of the protein in the elution fraction using the HA or the specific antibody. Compare with a yeast extract transfected with a control expression vector.

\section{6. $\beta$-Gal assays}

Three different $\beta$-galactosidase assays are described. The colony lift filter assay with the substrate X-Gal (5-bromo-4-chloro-3-indolyl- $\beta$-D-galactopyranoside) is a qualitative method similar to the on-plate assay. Both techniques allow the analysis of a large number of transformants appearing on the plates. However they are less sensitive than the liquid culture assay with the substrate ONPG (o-nitrophenyl- $\beta$-Dgalactopyranoside). The liquid culture assay allows the quantification of $\beta-\mathrm{Gal}$ activity. It can then be used to compare the relative strength of protein-protein interactions of different proteins or different mutations of the same protein. 
The colony lift filter assay and the ONPG assay use the freeze/thaw cycle in liquid nitrogen for the lysis of the cell walls. This is a rapid step for the accurate analysis of $\beta$-galactosidase activity.

For the on-plate assay X-Gal is added directly to the selective MM leading to a slight growth restriction because of a $\mathrm{pH}$ shift.

\subsubsection{Colony lift filter assay}

It is recommended to use fresh colonies (1-2 $\mathrm{mm}$ in diameter) that are growing on the selective MM. When colonies grown in presence of methionine have to be analysed, it is necessary that these transformants have not been plated on a 3ATcontaining medium (see subheading 3.4.).

1. For every plate to be assayed presoak a sterile 3MM Whatman paper in $2.5 \mathrm{ml}$ $(5 \mathrm{ml}) \mathrm{Z}-\mathrm{M}-X$-buffer in a $90 \mathrm{~mm}(150 \mathrm{~mm})$ plate. Lay, under sterile conditions, a dry nylon membrane filter on the yeast plate for few seconds to transfer the colonies onto the filter. Poke holes through the filter into the agar using hot needles in three asymmetric locations in order to orientate the filter compared to the plate for later assignments of positive clones.

2. Carefully remove the filter from the surface and lay it colony side-up on an aluminium boat, which floats on liquid nitrogen. After $10 \mathrm{sec}$, submerge the boat with the filter for $1 \mathrm{~min}$ and thaw it at room temperature. Place the filter colony sideup on the presoaked Whatman filter avoiding air bubbles under the filter.

3. Incubate at $30^{\circ} \mathrm{C}$ until blue colonies appear (from 30 min to 12 hours).

\subsubsection{Liquid culture assay}

In order to compare the results of different experiments in a statistical manner, we suggest the analysis of at least three separate colonies of each transformant.

1. Inoculate one colony in $10 \mathrm{ml}$ of the appropriate $\mathrm{MM}$ with or without $1 \mathrm{mM}$ methionine and incubate at $30^{\circ} \mathrm{C}$ under gentle shaking until the stationary phase (see note 4.5.). For further comparative studies it is important to have all cultures in the same growth phase.

2. Add approximately $16 \mathrm{ml}$ of $\mathrm{MM} \mathrm{(+/-} \mathrm{methionine)} \mathrm{to} 2 \mathrm{ml}$ of each culture to achieve an $\mathrm{OD}_{600}$ of $0.2-0.3$ and incubate for 3 hours at $30^{\circ} \mathrm{C}$ until the $\mathrm{OD}_{600}$ is in the range of $0.5-0.8$. Note the $\mathrm{OD}_{600}$ and the volume of the culture.

3. After centrifugation ( $5 \mathrm{~min}, 1000 \mathrm{~g}$ ), the cells are resuspended in $1 \mathrm{ml}$ of Z-buffer. Transfer to a $1.5 \mathrm{ml}$ microfuge tube and centrifuge at high speed for $20 \mathrm{sec}$. Discard the supernatant and dissolve the pellet in $250 \mu \mathrm{l}$ of Z-buffer. Divide the cell suspension into two $100 \mu \mathrm{l}$ aliquots and set up a standard reaction tube with $100 \mu \mathrm{l}$ Zbuffer.

4. Freeze the tubes 3 times for $1 \mathrm{~min}$ in liquid nitrogen and thaw them each time in a water bath.

5. Add to each tube $700 \mu \mathrm{l}$ Z-M-buffer and $160 \mu \mathrm{l}$ of freshly prepared Z-O-solution, incubate at $30^{\circ} \mathrm{C}$ until a yellow color develops. It is important to note the time of this reaction.

6. Stop the reaction by adding $400 \mu \mathrm{l} 1 \mathrm{M} \mathrm{Na}_{2} \mathrm{CO}_{3}$ solution. Centrifuge for $10 \mathrm{~min}$ at maximum speed to clear the supernatant and measure the $\mathrm{OD}_{420}$ against the standard.

The linear range of this assay lays in the area from 0.02 to 1.0 for an $\mathrm{OD}_{420}$. Calculate the $\beta$-Gal units using the following formula: $\beta-G a l=$ $1000 * \mathrm{OD}_{420} /\left(\mathrm{OD}_{600} * \mathrm{~V} * \mathrm{t}\right), \mathrm{V}=$ Volume of the culture and $\mathrm{t}=$ reaction time. With both $\mathrm{V}$ and $t$ constant you can simplify the formula to: $\beta-\mathrm{Gal}=1000 * \mathrm{OD}_{420} / \mathrm{OD}_{600}$

Using this technique, we could demonstrate that the formation of the CAKcomplex (Fig.4, lanes 1 and 2) is highly dependent on cyclin H. After 
cotransformation of the L40 strain with both pLex9-3H, containing LexA-cdk7 and Met25-cyclinH, and pVP16-MAT1, the $\beta$-Gal activity of such clones grown in a methionine-containing medium is less than $20 \%$ of the activity of colonies grown in a methionine-lacking one, due to the repression of the cyclin $\mathrm{H}$. The observed basal activity could be due to e.g. the leakiness of the Met25 promoter as discussed under subheading 3.4. In control experiments, yeast cotransformed with pLex9-3H, containing LexA-cdk7 and Met25-cyclin H, and native pVP16 (lane 3 and 4) or with pLex9-3H, containing only Met25-cyclin H, and pVP16-MAT1 (lanes 5 and 6) does not present any $\beta$-Galactosidase activity.

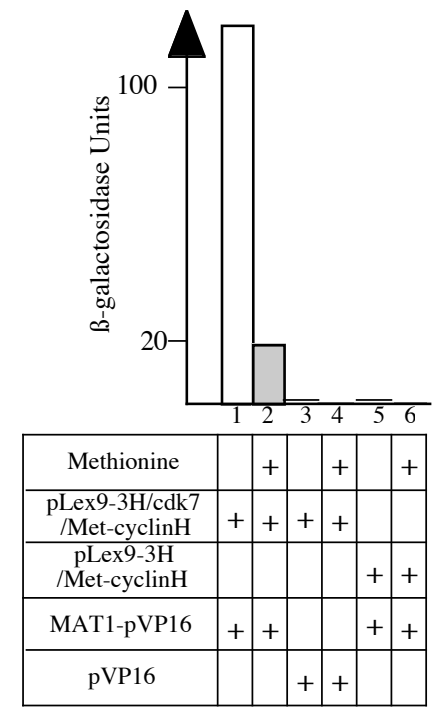

Figure 4: Liquid culture assay. L40 cells were cotransformed with the plasmids as indicated and analysed as described in subheading 3.6.2. with $\mathrm{V}=20 \mathrm{ml}$ and $\mathrm{t}=1 \mathrm{~min}$. In addition, the controls with vectors without fused protein were performed (lanes 3 to 6 ).

\subsubsection{On-plate assay}

$\beta$-Gal activity can be directly detected on the plates if the colonies are plated or replica-plated on a selective MM containing 1x S-buffer and 50 to $250 \mu 1 \mathrm{X}$-Gal solution and incubated at $28^{\circ} \mathrm{C}$. Blue color will appear with the colonies, after $4-8$ days.

\subsection{Inducible three-hybrid system:}

Three verifications for positive clones during the library screening

The three-hybrid system described here possesses an inducible promoter for the conditional expression of the third partner. This allows to perform an additional control of an interaction specificity, especially in a screening experiment for an activator. Once the positive clones are identified first by the appearance of the histidine prototrophy and second by their $\beta$-galactosidase activity (see note 4.6.), a third control can be done by transferring these positive clones onto a methionine containing medium as described under subheading 3.4. (see note 4.7.). Only the clones whose growth will be repressed by methionine will be considered as true positives. For the screening of a cDNA library to look for an inhibitor of a stable binary complex see note 4.8 .

\section{NOTES}




\subsection{Different systems for different tasks}

It is difficult to recommand a particular yeast strain for a random system. Because of the different properties concerning the activator system (GAL4 or LexA) and the promoter strength of the HIS3 or the other reporter genes, the appropriate strain has to be tested. The choice of the plasmids is also important because there are many differences in the number of copies per cell (high or low copy number). In addition, the promoter length of the alcohol-dehydrogenase I gene (ADH1), which controls the expression of the GAL4, LexA or VP16 fusion polypeptides, is varying between most of the commonly used plasmids. This leads to a different expression level of the fused proteins(10). There are also other vectors expressing the protein of interest fused to the N-terminus of LexA (11).

\subsection{Generation of the Met25-expression vectors}

The Met25-expression cassette, which contains the region from -474 to -1 of the Met25 promoter $(3,12)$, , the hemagglutinine epitope (HA), the nuclear localisation sequence and two rare restriction sites (NotI and SrfI for pLexA; NotI and BglII for pBridge) was cloned in the unique PvuII site of the plasmid vectors pBTM116 and pGBT9 to give the plasmids pLexA and pBridge, respectively. The transcription arrest signal is provided by addition of the phosphoglycerate kinase termination region corresponding to the BglII-HindIII terminator fragment from plasmid pEMBLYe30/2 (Fig.2, left panel)(8)..

It should be taken in account that the Met25 promoter is a strong promoter in the absence of methionine, compared to the ADH1 promoter. Therefore, the third polypeptide is much more expressed than the two other fused proteins.

\subsection{Methionine and other inducible promoters are possible}

There are several other three-hybrid systems using various inducible promoters :

- Galactokinase/galactose epimerase promoter (GAL1/GAL10), which is repressed by glucose and induced by galactose $(13,14)$. This promoter cannot be used in a GAL4 based two-hybrid system because the GAL4 activator binds the sequence between GAL1 and GAL10 and induces transcription.

- Acid Phosphatase promoter (PHO5), regulated by the presence or absence of inorganic phosphate (15).

- Metallothionein protein promoter (CUP1), induced by addition of copper to the medium $(16,17)$.

Some other promoters can be used for the regulated expression of the third partner in a three-hybrid system:

- Sorbitol dehydrogenase protein (SOR1), an enzyme responsible for sugar metabolism, is up regulated in presence of sorbitol. McGonigal et al. described some inducible protein expression vectors that can be used in a two or three-hybrid system (18).

- Aromatic aminotransferase II (ARO9) that catalyses the first step of tryptophan, phenylalanine and tyrosine catabolism in $S$. cerevisiae is upregulated by those aminoacids (19).

\subsection{Advantage of Microspin-columns}

Sometimes yeast extract immunoblot could be "smear-like" independently of the antibodies used. For optimum detection we found that filtering the yeast extract on a $0.45 \mu \mathrm{m}$ spin column can efficiently overcome this problem. Several techniques can be used such as affinity chromatography; however the advantages of the filter method reside mainly in the low cost and in time saving. 


\section{5. $\beta$-Galactosidase assay in function of the culture volume}

To analyse the strength of an interaction or the amount of hybrid proteins in the liquid ONPG-assay, it can be useful to test different volumes of yeast culture. We have noticed that, using low culture volume, the $\beta$-galactosidase activity measured was not in the linear range $\left(\mathrm{OD}_{600}\right.$ between 0.02 to 1.0$)$. Thus, further analyses should be done under the conditions found to be the most suitable. It has to be noticed that in the liquid ONPG-assay, weak (or background) interactions yield no yellow colour. The reaction can then be stopped if no yellow color has appeared after $30 \mathrm{~min}$.

\section{6. $\beta$-Galactosidase assays in cDNA library screening}

During the selection of positive clones by performing the on-plate and the colony lift filter assays in a yeast three-hybrid screening, only strong interactions are identified using the Y190 and L40 strains. Thus, the liquid culture assay is more sensitive for the identification of the weakest interactions in these strains.

\subsection{One more hybrid - one more control}

The two-hybrid system is used for detection of interaction between two proteins. Many interactions could not be detected because of the lack of specificity or because the right positioning of the interacting domains was not achieved. The three-hybrid system can overcome these problems by increasing the specificity of an interaction.

Thus, the presence of the third polypeptide is necessary to detect ternary complexes. One can imagine that a four-hybrid system can be used to detect quaternary complexes. Since many complexes involved in the different cellular processes contain more than three proteins, adding one more polypeptide to the bait means an increased specificity.

\section{8. cDNA library screening for an inhibitor}

To screen a cDNA library to search for a binary complex inhibitor, the methionine regulated system presented here is not appropriate. In presence of methionine, the repression of the inhibitor will lead to the formation of the transcriptional activator complex. Since each clone will express the reporter genes and will then be able to grow, replica-plating of all the corresponding colonies (approximately $2 \times 10^{6}$ ) will not be very practical. Therefore, a reverse three-hybrid system can be adapted from the system presented here (see chapter 24). But once a candidate is identified as an inhibitor, our system can be used to rapidly verify the inhibitory properties of the new protein. 


\section{References}

1. Vidal, M., and Legrain, P. (1999) Yeast forward and reverse 'n'-hybrid systems. Nucleic Acids Res 27, 919-29.

2. Brachmann, R. K., and Boeke, J. D. (1997) Tag games in yeast: the two-hybrid system and beyond. Curr. Op. Biotech. 8, 561-568.

3. Thomas, D., Cherest, H., and Surdin-Kerjan, Y. (1989) Elements involved in SAdenosylmethionine-mediated regulation of the Saccharomyces cerevisiae MET25 gene. Mol. Cell. Biol. 9, 3292-3298.

4. Devault, A., Martinez, A. M., Fesquet, D., Labbé, J. C., Morin, N., Tassan, J. P., Nigg, E. A., Cavadore, J. C., and Dorée, M. (1995) MAT1 ('ménage à trois') a new RING finger protein subunit stabilizing cuclin H-cdk7 complexes in starfish and Xenopus CAK. EMBO J. 14, 5027-5036.

5. Adamczewski, J. P., Rossignol, M., Tassan, J. P., Nigg, E. A., Moncollin, V., and Egly, J. M. (1996) MAT1, cdk7 and cyclin H form a kinase complex which is UV light-sensitive upon association with TFIIH. EMBO J. 15, 1877-1884.

6. Yankulov, K., and Bentley, D. L. (1997) Regulation of CDK7 substrate specificity by MAT1 and TFIIH. EMBO J. 16, 1638-1646.

7. Xiong, Y., Zhang, H., and Beach, D. (1993) Subunit rearrangement of the cyclindependent kinases is associated with cellular transformation. Genes Dev 7, 1572-83.

8. Tirode, F., Malaguti, C., Romero, F., Attar, R., Camonis, J., and Egly, J. M. (1997) A conditionally expressed third partner stabilizes or prevents the formation of a transcriptional activator in a three-hybrid system. J. Biol. Chem. 272, 22995-22999.

9. Vojtek, A. B., Hollenberg, S. M., and Cooper, J. A. (1993) Mammalian Ras interacts directly with the serine/threonine kinase Raf. Cell 74, 205-214.

10. Legrain, P., Dokhelar, M. C., and Transy, C. (1994) Detection of protein-protein interactions using different vectors in the two-hybrid system. Nucleic Acids Res. 22, 3241-3242.

11. Beranger, F., Aresta, S., de Gunzburg, J., and Camonis, J. (1997) Guetting more from the two-hybrid system: N-terminal fusions to LexA are efficient and sensitive baits for two-hybrid studies. Nucleic Acids Res. 25, 2035-2036.

12. Kerjan, P., Cherest, H., and Surdin-Kerjan, Y. (1986) Nucleotide sequence of the Saccharomyces cerevisiae MET25 gene. Nucleic Acids Res. 14, 7861-7871.

13. Johnston, M. (1987) A model fungal gene regulatory mechanism: the GAL genes of Saccharomyces cerevisiae. Microbiol Rev 51, 458-76.

14. Mylin, L. M., and Hopper, J. E. (1997) Inducible expression cassettes in yeast: GAL4. Methods Mol Biol 62, 131-48.

15. Bostian, K. A., Lemire, J. M., and Halvorson, H. O. (1983) Physiological control of repressible acid phosphatase gene transcripts in Saccharomyces cerevisiae. Mol Cell Biol 3, 839-53.

16. Labbe, S., and Thiele, D. J. (1999) Copper ion inducible and repressible promoter systems in yeast [In Process Citation]. Methods Enzymol 306, 145-53.

17. Mascorro, G. J., Covarrubias, A. A., and Gaxiola, R. (1996) Construction of a CUP1 promoter-based vector to modulate gene expression in Saccharomyces cerevisiae. Gene 172, 169-70.

18. McGonigal, T., Bodelle, P., Schopp, C., and Sarthy, A. V. (1998) Construction of a sorbitol-based vector for expression of heterologous proteins in Saccharomyces cerevisiae. Appl Environ Microbiol 64, 793-4.

19. Iraqui, I., Vissers, S., Andre, B., and Urrestarazu, A. (1999) Transcriptional induction by aromatic amino acids in Saccharomyces cerevisiae. Mol Cell Biol 19, 3360-71. 